Received: 24 April 2017

Accepted: 27 July 2017

Published online: 24 August 2017

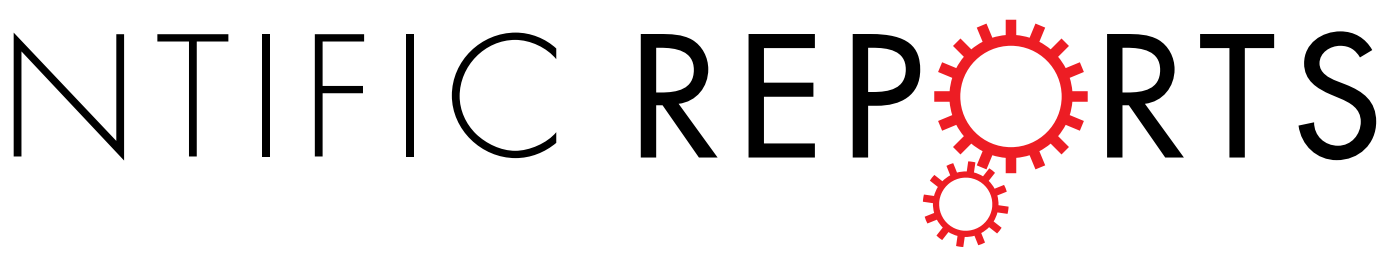

\title{
OPEN Combined effects of increased temperature and endocrine disrupting pollutants on sex determination, survival, and development across generations
}

\author{
Bethany M. DeCourten ${ }^{1}$ \& Susanne M. Brander ${ }^{1,2}$
}

Understanding the combined effects of anthropogenic impacts such as climate change and pollution on aquatic ecosystems is critical. However, little is known about how predicted temperature increases may affect the activity of endocrine disrupting compounds (EDCs), particularly in species with plasticity in sex determination. We investigated the effects of a concomitant increase in temperature and exposure to estrogenic EDCs on reproduction and development in an estuarine model organism (Menidia beryllina) across multiple generations. Parents $(P)$ were exposed to environmental levels of the estrogenic insecticide bifenthrin or ethinylestradiol (EE2) at $22^{\circ} \mathrm{C}$ and $28^{\circ} \mathrm{C}$ for 14 days prior to the initiation of spawning trials. Embryos in the F1 generation were exposed to EDCs until 21 days post hatch (dph), reared to adulthood in clean water at elevated temperatures, and spawned. F1 sex ratios were significantly influenced by elevated temperature and EDCs, potentially altering adaptive development. We also observed fewer viable offspring and increased developmental deformities in the F1 and F2 generations, with a greater impact on F2 juveniles. These findings enhance our understanding of responses to EDCs in the context of climate change and may demonstrate heritable effects. Our study represents the first multigenerational assessment of elevated temperatures in combination with environmentally relevant concentrations of commonly detected endocrine disruptors in a model vertebrate species.

Plasticity in sexual determination, often in response to environmental factors, is governed by a set of mechanisms that adjust sex ratio without altering genotype, and has evolved multiple times in poikilothermic taxa such as reptiles, amphibians and fish. For example, some organisms differentiate based on environmental cues, such as temperature ${ }^{1}$. This can occur when seasonal differences in development between the sexes optimizes adult fecundity, in some cases, allowing females to grow larger than males ${ }^{2-4}$. In stable populations, these skewed sex ratios typically average to a 1:1 ratio over time $\mathrm{e}^{5,6}$, however little is known about how organisms with this sensitive physiology may be influenced by anthropogenic stressors. For example, the increases in temperature associated with global climate change ${ }^{7}$ can lead to the disruption of reproductive outcomes in organisms with plasticity in sex determination $^{8-10}$. Fish species that tend to produce male-biased cohorts at higher temperatures, such as zebrafish and silversides, may also experience population decline with increasing temperature ${ }^{11}$, as the reproductive capacity of the population decreases. Since population growth is largely determined by female fecundity, increases in temperatures that cause a skew towards a male bias could lead to impaired populations under projected climate change scenarios ${ }^{12,13}$. Other environmental stressors, such as exposure to endocrine disrupting compounds (EDCs), can alter the sex ratio of organisms that have plasticity in sex determination ${ }^{14}$. EDCs are known to interfere with hormone signaling across $\operatorname{taxa}^{15}$, and elevated temperatures appear to increase the severity of EDC effects $^{16}$. Given that exposure to pollutants occurs within the context of global climate change, it is essential that

${ }^{1}$ Department of Biology and Marine Biology, University of North Carolina Wilmington, $601 \mathrm{~S}$. College Road, Wilmington, NC, 28403, USA. ${ }^{2}$ Department of Environmental and Molecular Toxicology, Oregon State University, 1007 Agricultural and Life Sciences Building, Corvallis, OR, 97331, USA. Correspondence and requests for materials should be addressed to B.M.D. (email: bmd5520@uncw.edu) 
we understand the combined implications in species with sensitive physiology, especially those inhabiting highly impacted areas such as estuaries ${ }^{17}$. Understanding their collective effect(s) is of particular concern since both rising temperatures and endocrine disrupting compounds (EDCs) have been separately linked to altered growth, decreased sperm motility, impaired embryo development, reduced fecundity, altered behavior, and decreased survival of fish at early, more sensitive, life stages ${ }^{18-20}$.

The EDCs bifenthrin (BF, pyrethroid pesticide) and ethinylestradiol (EE2, oral contraceptive) are commonly used in developed countries and frequently contaminate watersheds ${ }^{21,22}$. Both compounds alter estrogen signaling in fishes at environmentally relevant concentrations ${ }^{15}$. Bifenthrin has been shown to impair development and to reduce reproductive success in fish by influencing hormone levels, reproductive behavior and development of gametes, decreasing the gonadal-somatic-index (GSI) in fish and hindering the development of healthy ovarian follicles $^{16,18,23,24}$. Because the metabolite of bifenthrin is a more potent estrogenic endocrine disruptor than the parent compound ${ }^{25}$ we expect that elevated temperature will influence its toxicity as metabolic rates increase with temperature ${ }^{26}$. The well-studied synthetic estrogen, EE2, has been shown to affect behavior, reproduction, and development ${ }^{9,14,22,27,28}$. As a potent estrogen, EE2 has been used in other studies as a positive control when testing for the estrogenic effects of other compounds ${ }^{29,30}$.

The inland silverside (Menidia beryllina) is a widespread estuarine species of ecological importance with a short generation time (6-8 months $)^{23,31}$. M. beryllina, which is thought to exhibit plasticity in sex determination, as other Menidia species do $\mathrm{do}^{32}$, is also highly sensitive to $\mathrm{EDCs}^{14,18,33}$. Our objective was to assess how exposure to commonly detected EDCs (EE2, BF) at environmentally relevant levels $(1 \mathrm{ng} / \mathrm{L})^{22,34}$ affects sex ratio and reproductive success in an organism with said plasticity. Since multigenerational studies are important for determining long-term effects of stressors in wild populations ${ }^{35}$, we examined the relationship between elevated temperature (F0, F1, F2) and EDCs (F0, F1) in M. beryllina over three generations.

The critical temperature necessary to maintain a female-biased sex ratio in other Menidia species closely related to $M$. beryllina, which have a temperature sensitive period continuing until roughly 21 days post hatch (dph), is $\leq 25^{\circ} \mathrm{C}$, above which the population begins to skew toward a male bias ${ }^{2}$. We chose to test a temperature near the upper thermal limit at which $M$. beryllina are observed spawning in the wild $\left(28^{\circ} \mathrm{C}\right)$ to ensure spawning success $^{31}$ and compared this to an ambient temperature of $22^{\circ} \mathrm{C}$. The $28^{\circ} \mathrm{C}$ temperature represents the worst-case scenario of mean global temperature increases modeled by the more extreme (RCP 8.5) models put forth by the Intergovernmental Panel for Climate Change ${ }^{7}$. As such, we exposed adult fish (F0) to EDCs at $22^{\circ} \mathrm{C}$ and $28^{\circ} \mathrm{C}$ for 14 days prior to spawning. The F1 generation was exposed from gamete to larval stages (to $21 \mathrm{dph}$ ), then reared to adulthood in clean water at the experimental temperatures. This period of approximately 35 days is relevant to that of a pulse exposure in the wild ${ }^{36}$. The F2 generation did not undergo any chemical exposure, to test for the heritability of the observed effects (Supplemental Fig. 1). We hypothesized that EDCs would reduce egg production and offspring production, with stronger effects measured at higher temperatures, and that sex ratios would be influenced by estrogenic EDC (BF or EE2) exposure. We hypothesized that the F2 generation, only exposed indirectly as germ cells to EDCs, would exhibit effects similar to those of generations exposed to both a warmer temperature and EDCs. To the best of our knowledge, this is the first study to combine an assessment of environmentally relevant stressors in the context of climate change over multiple generations in a model vertebrate species.

\section{Results and Discussion}

Our study demonstrated that sex ratios of M. beryllina can be influenced by abiotic stressors, similar to that of their congeners (binomial GLM, $n=26, p=0.01215$, Fig. 1) ${ }^{1,32}$. We did not detect any significant differences in sex ratio among EDC treatments at the ambient temperature $\left(22^{\circ} \mathrm{C}\right)$. However, the proportion of females in the warm EE2 $\left(28^{\circ} \mathrm{C}\right)$ treatment was significantly greater than that in the warm and ambient controls (binomial GLM followed by Tukey HSD, $n=4$ per treatment, $\mathrm{p}=5.7 \times 10^{-5}, \mathrm{p}=0.0144$, respectively; Fig. 1 ). We also found that the sex ratios in the $28^{\circ} \mathrm{C} \mathrm{BF}$ and EE2 significantly differed (binomial GLM followed by Tukey HSD, $\mathrm{n}=4$ per treatment, $p=0.0116$, Fig. 1), confirming that EE2 acts as a more potent estrogen. Although the difference between controls was not significant at the 0.05 alpha level, the low p-value (0.0588) (binomial GLM followed by Tukey HSD, $\mathrm{n}=4$ per treatment,), suggests that this species may adhere to the expected pattern of a male biased sex ratio at warmer temperatures ${ }^{1}$ (Fig. 1). The difference in sex ratio between temperatures observed in the EE2 treatments, although not significant (binomial GLM followed by Tukey HSD, $n=4-5$ per treatment, $p=0.0703$ ) contradicts the expected influence of temperature on sex ratio based on studies with closely related species, in which the sex ratio is expected to skew toward a male bias at elevated temperatures ${ }^{1}$ (Fig. 1). Our findings suggest that estrogenic EDCs may be able to inhibit or reverse the expected sexual differentiation at high temperatures in fish with sexual plasticity. A recent study demonstrated a similar response in zebrafish, with exposure to estrogens inhibiting masculinization of fish at higher temperatures ${ }^{9}$. Another study showed that development can be influenced by thermal fluctuations in fish, in some cases causing sex reversal in the fathead minnow ${ }^{37}$. Our data support these findings and suggest that both elevated temperatures and exposure to estrogenic EDCs can disrupt sexual differentiation in fish. Plasticity in sex determination is favored when a temporal difference between production of male and female offspring increases fitness of the population ${ }^{1}$. Our results indicate that presence of EDCs may counteract the adaptive advantage of plastic sex determination, potentially increasing the risk of population collapse.

Developmental deformities were observed throughout the rearing of the F1 and F2 generations. Deformed fish were smaller and darker than healthy fish, and exhibited a varying degree of caudal fin deformities (Supplemental Image 1). There were threefold more deformed F1 adults (Fig. 2A) collectively in BF treatments than in controls and EE2 (binomial GLM followed by Tukey HSD, $n=4-5$ per treatment, $\mathrm{p}=0.0042$, Fig. 2 ) treatments, with no effect of temperature observed. Because the $\mathrm{F} 2$ generation was not reared to adulthood, deformities were assessed during the $21 \mathrm{dph}$ sampling. Presence of deformities in the unexposed F2 generations show that these effects 


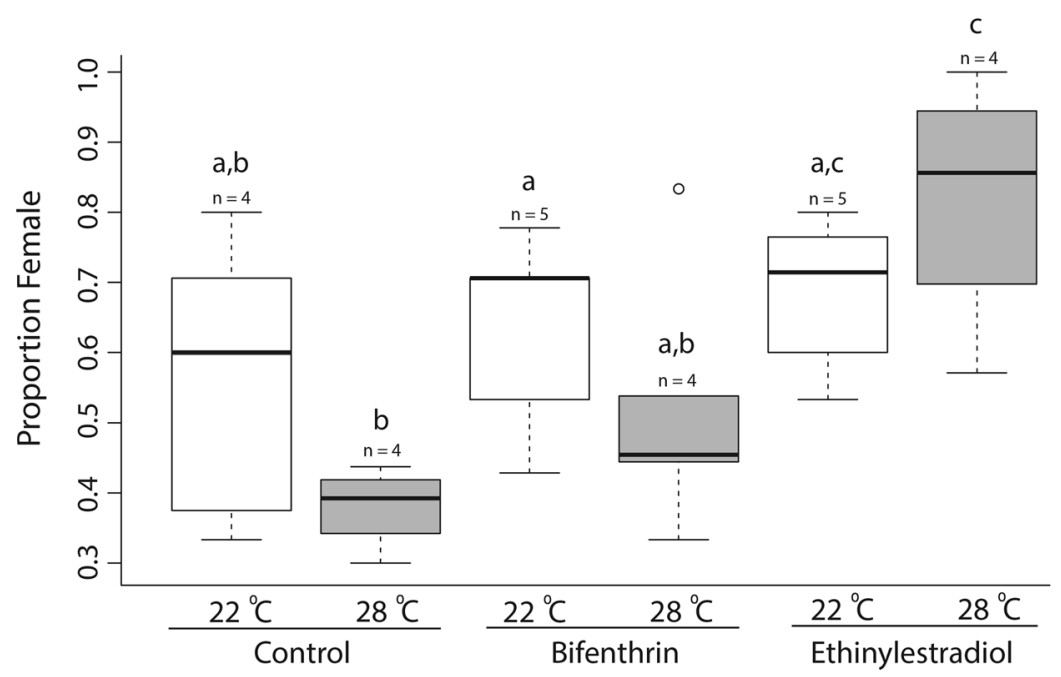

Figure 1. Box plot of the proportion of females in the F1 generation by treatment, demonstrating plasticity in sexual determination in $M$. beryllina. Boxes denote the inter-quartile range and whiskers represent the upper and lower quartiles, with median denoted solid bars. Treatments that share the same lowercase letters are not significantly different $(p<0.05)$. Lowercase " $n$ " represents the number of replicate tanks in each treatment.

A

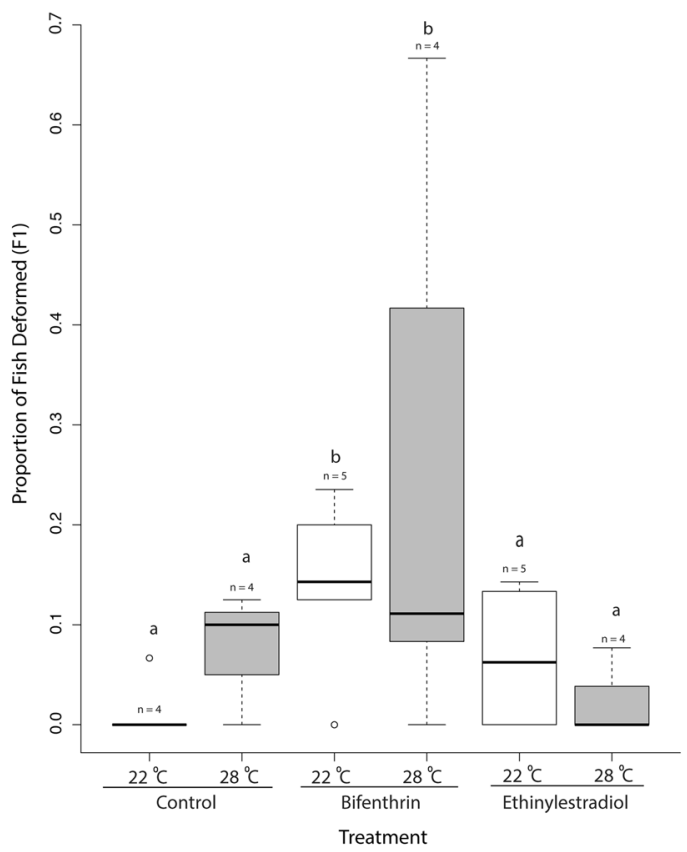

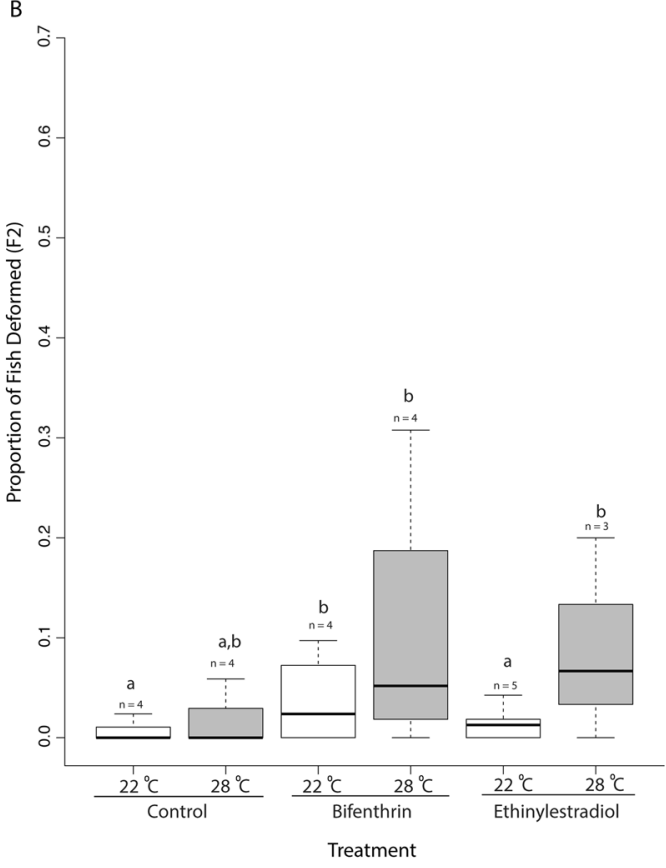

Figure 2. Box plot of the proportion of F1 adults and F2 larvae exhibiting developmental deformities. Boxes denote the inter-quartile range and whiskers represent the upper and lower quartiles, with median denoted solid bars Treatments that share the same lowercase letters are not significantly different $(p<0.05)$. Lowercase " $n$ " represents the number of replicate tanks in each treatment.

can be transferred to subsequent generations either due to indirect exposure of primordial germ cells (contained within F1 parents) or epigenetically. There was a higher proportion of deformed F2 larvae (Fig. $2 \mathrm{~B}$ ) in the $22^{\circ} \mathrm{C} \mathrm{BF}$, $28^{\circ} \mathrm{C} \mathrm{BF}$ and $28^{\circ} \mathrm{C} \mathrm{EE} 2$ treatments compared to the $22^{\circ} \mathrm{C}$ control indicating that the full effect of EDCs on development may not be realized in a single generation (binomial GLM, followed by Tukey HSD, $\mathrm{n}=4-5$ per treatment, $\mathrm{p}=0.00787, \mathrm{p}=0.00329, \mathrm{p}=0.0038$, respectively, Fig. 2B). There were six-fold more deformed larvae in the $28^{\circ} \mathrm{C}$ EE2 ( $\mathrm{n}=4$ per treatment) than $22^{\circ} \mathrm{C} \mathrm{EE} 2$ (binomial GLM followed by Tukey HSD, $\mathrm{n}=5$ per treatment, $\mathrm{p}=0.00576$, Fig. $2 \mathrm{~B}$ ) treatments, showing that temperature can exacerbate the development of deformities following parental EDC exposure. Estrogenic chemicals have been shown to cause developmental abnormalities and to impair locomotor function in fish exposed to the chemical as embryos ${ }^{16}$. Deformities in this study following EDC exposure resulted in impaired caudal development and swimming capabilities which could have a strong effect 

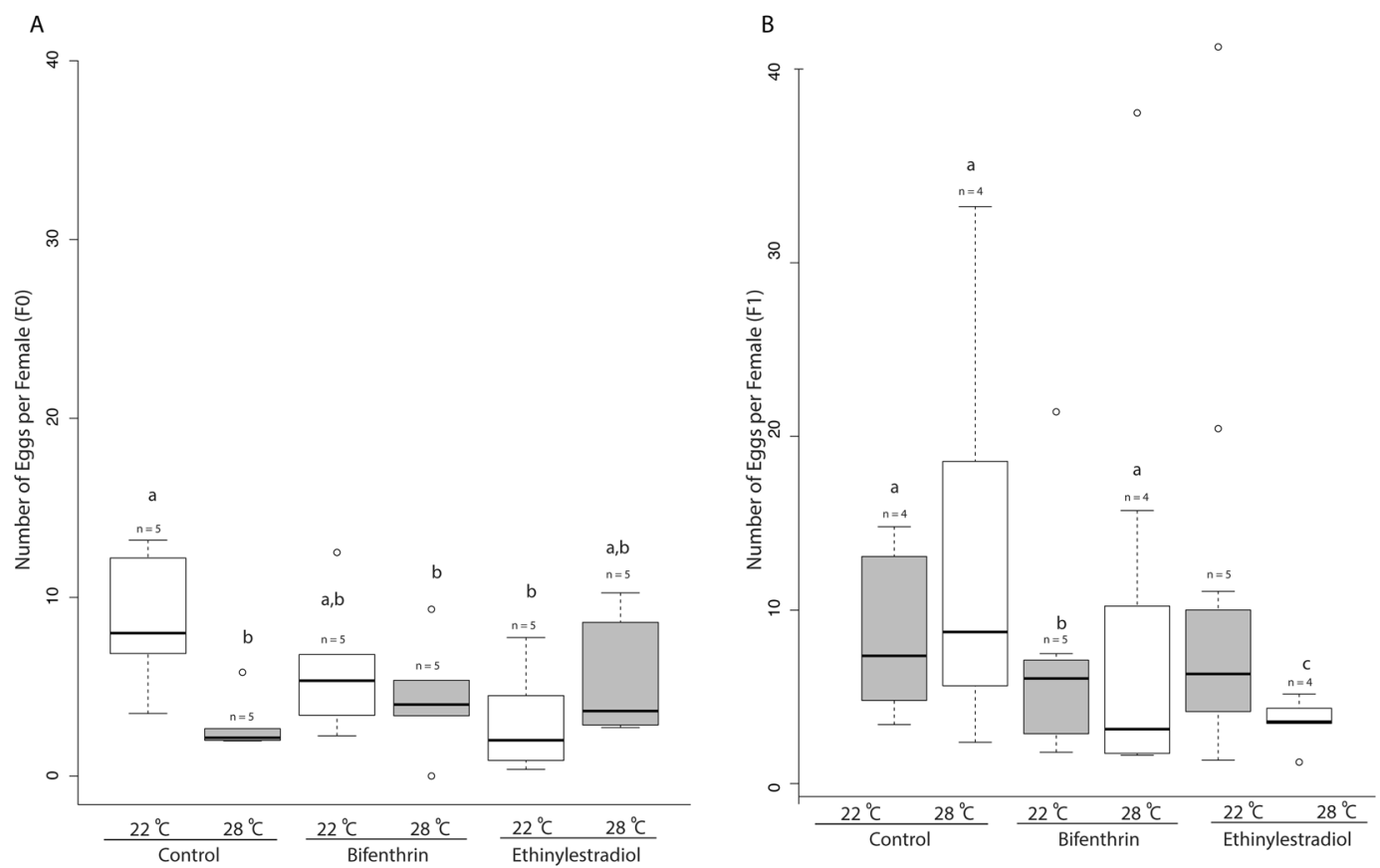

Figure 3. Box plot of the eggs produced in spawning trials (per female) in the F0 generation (A) and F1 generations (B). Boxes denote the inter-quartile range and whiskers represent the upper and lower quartiles, with median denoted solid bars. Treatments that share the same lowercase letters are not significantly different $(p<0.05)$. Lowercase " $n$ " represents the number of replicate groups in each treatment.

on feeding success and predator avoidance in a natural habitat ${ }^{38}$. In the F2 generation, there was an effect of both EDCs, with EE2 effects only apparent at higher temperature, indicating that the response is influenced by temperature. It was previously demonstrated that deformities following parental exposure to EDCs can have heritable effects on morphological deformities in subsequent generations ${ }^{39}$. Our results suggest that deformities may not only be heritable but may worsen in subsequent generations. These data do not indicate whether populations will be able to adapt to chronic exposure to anthropogenic stressors.

We found that an increase in temperature (to $28^{\circ} \mathrm{C}$ ) reduced the average number of eggs produced per female (Fig. 3A) in the F0 generation control groups and (Poisson GLM followed by Tukey HSD, $\mathrm{n}=5$ per replicate, $\mathrm{p}=0.00239$ ). When compared to the $22^{\circ} \mathrm{C}$ control we found that $\mathrm{EE} 2$ and $\mathrm{BF}$ significantly reduced the number of eggs in $22^{\circ} \mathrm{C}$ and $28^{\circ} \mathrm{C}$ respectively (Poisson GLM followed by Tukey HSD, $n=5$ per treatment, $\mathrm{p}=0.00239$ ). These results suggest that $\mathrm{BF}$ acts as a more potent estrogen at higher temperatures, likely due to higher rates of conversion into the more potent metabolite ${ }^{25}$. Conversely, the opposite was found in the EE2 treatments suggesting that this chemical is less potent at higher temperatures. These effects differed from the effects observed in the $\mathrm{F} 1$ generation (Fig. $3 \mathrm{~B})$ where we found a reduction in egg production following exposure to $\mathrm{BF}\left(22^{\circ} \mathrm{C}\right.$, Poisson GLM followed by Tukey HSD, $n=5$ per treatment, $\mathrm{p}=0.00119$, Fig. $3 \mathrm{~B}$ ), and the largest reduction of egg production in the EE2 $\left(28^{\circ} \mathrm{C}\right.$, Poisson GLM followed by Tukey HSD, $\mathrm{n}=4$ per treatment, $\mathrm{p}=1.06 \times 10^{-5}$, Fig. 3B) when compared to the controls. These data confirm that EE2 is a highly potent EDC capable of causing reduced fecundity as seen in previous studies ${ }^{40,41}$. We detected differences between the $22^{\circ} \mathrm{C}$ and $28^{\circ} \mathrm{C}$ groups for both $\mathrm{BF}$ (Poisson GLM followed by Tukey HSD, $\mathrm{n}=4$ per treatment, $\mathrm{p}=0.0175$ ) and EE2 (Poisson GLM followed by Tukey HSD, $\mathrm{n}=4$ per treatment, $\mathrm{p}=4.81 \times 10^{-5}$ ) (Fig. 3 ). The fecundity of $M$. beryllina slows as temperatures approach the critical limit of $31^{\circ} \mathrm{C}$, after which spawning ceases ${ }^{31}$. Separately, it has been shown that both low levels of estrogenic compounds and elevated temperatures can decrease egg production in fish ${ }^{18,40,42}$, however literature is lacking on the potential interactions of these stressors and the effects on fecundity. Our results indicate that when combining these stressors temperature can influence the effects of EDCs on egg production, as we did not detect differences between temperatures in the control groups. In accordance with the results from the spawning assays, we also found that female gonadal somatic index (GSI) (F0, F1) decreased (Supplemental Fig. 2) following temperature increases and EDC exposure (two-way ANOVA, $\mathrm{n}=4-5, \mathrm{p}<0.03$ ). Previous studies with estrogenic compounds have shown that these EDCs can reduce gonadal size, thus decreasing reproductive capacity $^{15,33,42}$. Our results support these findings and expand upon the possible interaction of elevated temperature and EDC exposure.

Larval production (assessed at $21 \mathrm{dph}$, incorporating both hatch and early survival) decreased in all $28^{\circ} \mathrm{C}$ treatments (F2) when compared to the $22^{\circ} \mathrm{C}$ control (two-way ANOVA followed by Tukey HSD, $\mathrm{n}=4$ per treatment $(\mathrm{EE} 2$ and $\left.\mathrm{MeOH}) \mathrm{n}=5(\mathrm{BF}), \mathrm{p}<2.00 \times 10^{-16} \mathrm{Fig} .4 \mathrm{~B}\right)$. Within the $22^{\circ} \mathrm{C}$ treatments the fewest larvae were produced in the BF treatments (two-way ANOVA followed by Tukey HSD, $\mathrm{n}=5$ per treatment, $\mathrm{p}<3.41 \times 10^{-14}$, Fig. $4 \mathrm{~B}$ ) followed by the EE2 treatments (two-way ANOVA followed by Tukey HSD, $\mathrm{n}=4$ per treatment, $\mathrm{p}=0.00373$; Fig. $4 \mathrm{~B}$ ). Offspring quantities in the F2 generation were affected by both EDC exposure 

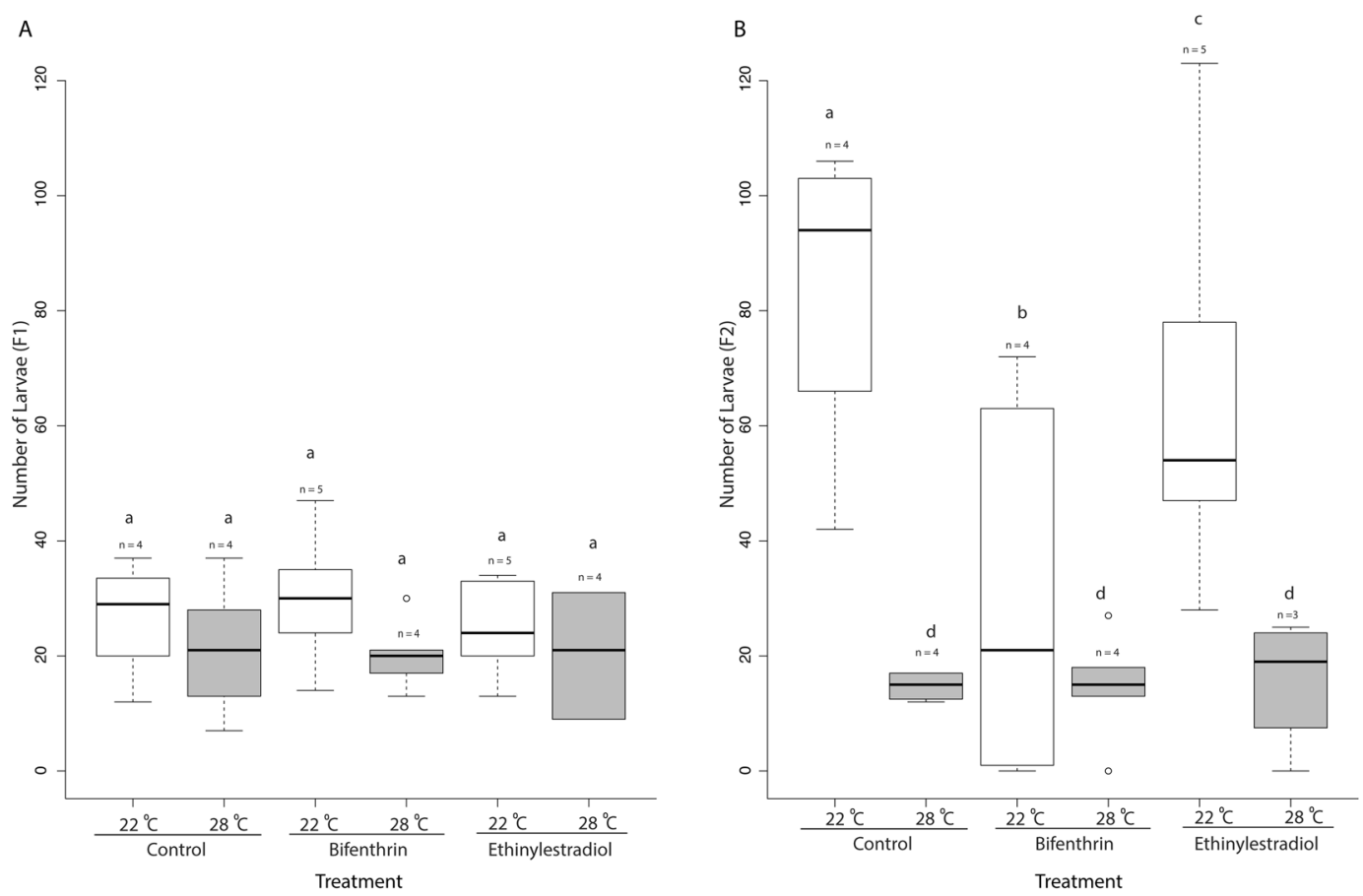

Figure 4. Box plot of the number of larvae assessed at $21 \mathrm{dph}$ produced in the F1 generation and F2 generations. Boxes denote the inter-quartile range and whiskers represent the upper and lower quartiles, with median denoted solid bars. Treatments that share the same lowercase letters are not significantly different $(p<0.05)$. Lowercase " $n$ " represents the number of replicate tanks in each treatment.

and temperature increases with a greater reduction in larvae than the previous generation, as there were no significant differences between treatments in the F1 generation (Fig. 4A). These results indicate that the severity of these effects may not be realized within a single generation as previously observed with estrogenic EDCS ${ }^{43}$. Additionally, this suggests that offspring response to EDCs is dependent on the timing of parental exposure. F1 larvae were produced following parental exposure at the adult stage, as opposed to the F2 larvae which were produced following parental exposure at the larval stage. These results support the idea that exposure to EDCs at early life stages may have stronger heritable effects than exposures at adult stages ${ }^{44}$. This study suggests that increasing temperatures associated with climate change may negatively impact the reproductive output and viability of offspring of Menidia species in North America and Atherinid species in general, which are found in numerous temperate zones globally. Temperate fish exposed continuously to higher temperatures without seasonal winter cooling produce lower quality offspring due to reduced size and nutritional quality of the eggs produced $^{45}$, possibly reducing offspring viability. Furthermore, offspring production in fish exposed indirectly as primordial germ cells, as our F2 generation was, can also be reduced ${ }^{41}$. This supports the idea that populations exposed to EDCs may not be able to adapt to estrogenic EDC exposure as temperatures increase, with deleterious effects persisting throughout generations ${ }^{40}$. To confirm this, future assessments should be conducted at least through the F3 or ideally through the F4 generation.

In closely related Menidia species, producing more females at colder temperatures (representative of early spawning months) allows them to mature earlier, grow larger (fecundity increases with female size), and produce more eggs over the entirety of the spawning season ${ }^{32}$. Results from this study suggest that combined exposure to elevated temperature and/or EDCs alters sex ratios, reduces offspring number, and hinders their development. Some effects of these stressors were shown to impact subsequent generations, suggesting that anthropogenic stressors can cause persistent population level effects. The implications of this study extend to other vertebrates with plasticity in sex determination, as members of many taxa (i.e., reptiles and amphibians) exhibit similar responses to temperature change and EDCs. For example, in some reptiles elevated temperature can lead to a female-biased sex ratio, as opposed to a male-biased sex ratio as in Menidia species, and can also affect the development of offspring ${ }^{3}$, as we observed here. In the face of global climate change, silversides and other similarly adapted species may experience greater population declines due to reduced population-level fecundity and a decrease in viable offspring. It has been shown that temperature increases expected under current climate change projections will lead to population collapse, possibly within the next 50 years, particularly for species with temperature-dependent plasticity in sexual development in populations that are already threatened ${ }^{46,47}$. Our study demonstrates that the risk of collapse may be exacerbated in contaminated waterways, even at relatively low concentrations of chemicals ( $1 \mathrm{ng} / \mathrm{L}$ ), possibly leading to more rapid localized extinction events. Our results also imply that some of the effects of temperature on reproduction, such as decreased larval production, are measureable in subsequent generations, especially when combined with exposure to endocrine disruptors. Additional 
research is necessary to determine the potential additive or synergistic effects of multiple anthropogenic stressors across generations, within a changing climate, to understand the potential for long-term population-level effects.

\section{Methods}

Rearing of parental fish. Fish in the parental generation $(\mathrm{P})$ were obtained from Aquatic Biosystems (Fort Collins, CO) at 30 days post hatch (dph) and reared to adulthood in $25^{\circ} \mathrm{C}, 15 \mathrm{ppt}$ water at the University of North Carolina, Wilmington's Center for Marine Science. Fish were fed a diet of Hikari tropical micro pellets (Kyorin Food Industries, Ltd, Japan) and live Artemia nauplii supplemented with Selcon ${ }^{\text {TM }}$ (American Marine Inc., Ridgefield, CT), during rearing and experimental periods. Adult fish (341 dph) were transported to experimental chambers and acclimated to either $22^{\circ} \mathrm{C}$ or $28^{\circ} \mathrm{C}$ for 3 weeks prior to experimental exposures under a continuous 16:8 light-dark cycle. Fish in the F0 generation were separated into 5 replicate jars containing 10-13 for each treatment and temperature used in the study.

EDC exposures. Parental exposures were initiated by replacing approximately 90 percent of the water in experimental tanks with water containing the target concentration of chemicals used in the study. For the control groups, $1 \mathrm{~mL} / \mathrm{L}$ of methanol was added to control for any effects that could be attributed to the solvent, inbreeding depression, or experimental heat and handling stress. BF and EE2 treatments contained $1 \mathrm{ng} / \mathrm{L}$ of bifenthrin (purity: 99.5\%, Chem Service, West Chester, PN) or 1ng/L 17 $\alpha$-ethinylestradiol (EE2) (purity: $\geq 98 \%$, Sigma-Aldrich, St. Louis, MO), respectively, suspended in $1 \mathrm{~mL} / \mathrm{L}$ of methanol due to the hydrophobic nature of the EDCs. Adult fish (F0, $248 \mathrm{dph}$ ) were exposed for 14 days in $7.6 \mathrm{~L}$ glass jars, containing approximately $6 \mathrm{~L}$ of artificial seawater. F1 embryos were produced during the parental exposure and continued until all larvae had reached $21 \mathrm{dph}$, approximately the time of sexual determination. Exposure jars were placed in $60 \mathrm{~L}$ water baths using aquarium heaters to maintain temperature (21.9 \pm S.D. 0.41 and $27.7 \pm$ S.D. 0.89 , for temperature treatments respectively). Fish were maintained at a constant salinity target of 15 ppt optimal for growth and survival in M. beryllin $a^{36}$. Artificial seawater (15 ppt) was made daily by adding Instant Ocean to distilled water and aerated for 24 hours prior to use. Solutions with experimental chemicals were mixed in glass containers, immediately prior to daily water changes. Jars were continuously aerated and water quality parameters including temperature (21.9 \pm S.D. 0.41 and $27.7 \pm$ S.D. 0.89 , for temperature treatments respectively), dissolved oxygen (5.81 \pm S.D. $0.98), \mathrm{pH}$ (7.94 \pm S.D. 0.56), salinity (16.26 \pm S.D. 1.59), and ammonia (0.22 \pm S.D. 0.76$)$ were measured with a YSI Professional Plus Quatro water quality meter daily before and after water changes in two representative control jars at each temperature. Temperature of water baths was measured once daily for the duration of the experiment. Sixty percent of the water was removed and replaced daily following thorough removal of debris in experimental chambers. All air pumps and heaters were connected to an emergency power source to ensure continuous function. Adult fish were fed a diet of Hikari fish food pellets, freeze-dried blood worms and live Artemia nauplii supplemented with Selcon ${ }^{\mathrm{TM}}$ (vitamin supplement). Larvae were fed live rotifers (Brachionus rotundiformis) from 0-14 dph, and a combination of live Artemia and ground Hikari pellets from $10 \mathrm{dph}$ to adulthood. Fish were fed daily and allowed to feed for one hour prior to water change. Following exposures, spawning trials were initiated with the parental generation adults, and F1 larvae were transferred to clean tanks and reared to adulthood at experimental temperatures.

Analytical Chemistry. Water samples to control for methods were mixed using experimental methods and materials in $950 \mathrm{~mL}$ sterile amber bottles, transported on wet ice and stored in the dark at $4{ }^{\circ} \mathrm{C}$ for no longer than 24 hours. Extraction was performed using conditioned $6 \mathrm{~mL}$ solid phase-extraction $\mathrm{C}_{18}$ cartridges (Superclean ${ }^{\mathrm{TM}}$ $500 \mathrm{mg}$, Sigma- Aldrich) at a slow drip. Columns were rinsed twice with $5 \mathrm{~mL}$ of a 1:1 solution of hexane:ethyl acetate to elute the bifenthrin. The solvent elution $(10 \mathrm{~mL})$ was concentrated to $0.4 \mathrm{~mL}$ under a gentle stream of nitrogen. Final extract was analyzed using gas chromatography negative chemical ionization mass spectrometry (GC-NCI-MS) on an Agilent 5973 series gas chromatograph (Agilent Technologies, Palo Alto, CA) equipped with a split-splitless injector $\left(280^{\circ} \mathrm{C}\right.$, splitless, $1.5 \mathrm{~min}$ purge time). The columns used were Supelco DB- $5 \mathrm{MS}$ column $(30 \mathrm{~m} \times 0.25 \mathrm{~mm}$ with a $0.3 \mu \mathrm{m}$ film thickness). The instrument was calibrated using nine sets of standard bifenthrin solutions, the surrogate trans-permethrin D6 (EQ Laboratories, Atlanta, GA), and the internal standard dibromooctafluorobiphenyl (Chem Service, West Chester, PA) in hexane. Controls were conducted by analyzing a method blank of deionized water (Milli-Q) to ensure samples were not contaminated. The Surrogate was added to each sample before extraction to monitor matrix effects and method performance. The detection limit of bifenthrin in whole water was $0.6 \mathrm{ng} / \mathrm{L}$. No bifenthrin was detected in the controls or method blank. Measured concentrations of bifenthrin were $1.3 \mathrm{ng} / \mathrm{L}$. Surrogate recovery ranged from $133.84 \%$, with corrected value of bifenthrin concentration being $0.89 \mathrm{ng} / \mathrm{L}$. Analytical chemistry was not performed on EE2 treatment water, but those solutions were made according to previously established protocols ${ }^{18,25}$. All stock and experimental solutions were mixed in the same manner as bifenthrin to ensure like concentrations.

Spawning assay. On day 14 of parental exposures, a single spawning trial including 8-15 adult fish (depending on exposure mortality) for the parental generation and 9-18 fish for the F1 generation, was initiated by the addition of spawning substrate ( 6 inch strands of bleached and rinsed dye free yarn), as described in Brander et al. ${ }^{18}$. Substrate remained in the tanks for $24 \mathrm{~h}$ before removal. The spawning trial with adults from the $\mathrm{F} 1$ generation were initiated at time of maturity, to test the effects of larval exposure only. F1 spawning trials were extended to 48 hours to increase the likelihood of spawning. Fertilized and unfertilized eggs were counted under a dissecting microscope to assess reproductive output. After a $24 \mathrm{~h}$ recovery period following the spawning trial, new spawning substrate was added to each jar and fish were allowed to spawn for $48 \mathrm{~h}$ to produce the embryos of the subsequent generation. After the spawning assays, all adult fish were euthanized in an overdose solution of MS-222 and immediately weighed, measured and dissected to determine sex and gonadal somatic index (GSI). 
Larval rearing. Spawning substrate from the second spawning event remained in experimental jars allowing attached embryos to hatch without transfer. All F1 larvae were reared with chemical exposure until $21 \mathrm{dph}$ at which point a subset of 5 larvae were sampled at $21 \mathrm{dph}$, weighed and measured to obtain morphometric data and preserved to be used for later molecular analysis and all remaining fish were transferred to clean $37.5 \mathrm{~L}$ round black polypropylene tanks to be reared to sexual maturity at either $22^{\circ} \mathrm{C}$ or $28^{\circ} \mathrm{C}(21.9 \pm$ S.D. 0.41 and $27.7 \pm$ S.D. 0.89 , for temperature treatments respectively). Each tank was equipped with Marineland Penguin PF0100B filter, one Eheim Jager aquarium thermostat heater (75 watt) and Resun AF-2009D automatic feeder. F2 larvae were spawned and reared in clean water at experimental temperatures until $21 \mathrm{dph}$, to test the effect of parental exposure on offspring morphology and viability. At this time time, all larvae were sampled and the experiment was terminated. All experiments were conducted in accordance with UNCW Institutional Animal Care and Use Committee (IACUC) protocol \#A1314-010 and \#A1415-010. These protocols included methods for all experiments involving live animals, and were approved by UNCW IACUC prior to experimentation.

Statistical analysis. We tested for significant differences with each endpoint using generalized linear models, followed by Tukey's post hoc comparisons (GLM) Morphometric data (SL and mas) obtained from all fish used in spawning trials (9-18 per replicate), a subset of larvae (5 per replicate, $21 \mathrm{dph}$ ) in the F1 generation and all larvae produced (maximum of 50) in the F2 generation ( $21 \mathrm{dph}$ ). We tested for differences in morphometric data using an ANCOVA ( $n=5$ and $n=4$ for the parental and F1 generations respectively) followed by Tukey's post-hoc comparison. For all post-hoc comparisons, p-values were calculated in a manner that preserved a 0.05 false discovery rate ${ }^{48,49}$. We tested for differences in egg production by standardizing the number of eggs produced, by the number of females in each jar before using a generalized linear model (log link, Poisson error distribution), followed by Tukey's post hoc comparisons. Differences in sex ratios of fish used in the F1 spawning trial (10-15 per replicate) were tested using a generalized linear model (binomial distribution) followed by Tukey's post hoc comparisons comparison. We tested for differences in the proportion of deformed fish observed at the time of sampling in the F1 (10-15 per replicate) and F2 (all remaining fish in each replicate) generations using a binomial generalized linear model and Tukey's post hoc comparison. For further information on the number of fish in each replicate please refer to Supplemental Table 2. All statistical analyses were performed in R (v 3.3.1); post-hoc comparisons were made using package multcomp ${ }^{49}$. The datasets generated during and/or analysed during the current study are available from the corresponding author on reasonable request.

\section{References}

1. Conover, D. O. \& Kynard, B. E. Environmental sex determination; interaction of temperature and genotype in a fish. Science. 213(31), 577-579 (1981).

2. Strüssmann, C. A., Conover, D. O., Somoza, G. M. \& Miranda, L. A. Implications of climate change for the reproductive capacity and survival of New World silversides (family Atherinopsidae). Journal of Fish Biology. 77(8), 1818-1834, doi:10.1111/j.1095-8649.2010.02780.x (2010).

3. Warner, D. A. \& Shine, R. Interactions among thermal parameters determine offspring sex under temperature-dependent sex determination. Proceedings of the Royal Society of London B: Biological Sciences 278(1703), 256-265, doi:10.1098/rspb.2010.104 (2010).

4. Murray, C. M., Easter, M., Padilla, S., Mahmood, S. \& Guyer, C. Regional Warming and the Thermal Regimes of American Crocodile Nests in the Tempisque Basin, Costa Rica. Journal of Thermal Biology. 60, 49-59 (2016).

5. Conover, D. O. \& Van Voorhees, D. A. Evolution of a Balanced Sex Ratio by Frequency-Dependent Selection in a fish. Science. 250 (4987), 1556-1558. 10.1126/science.250.4987.1556

6. Fisher, R. A. The genetical theory of natural selection: a complete variorum edition. Oxford University Press. (1930)

7. Stocker, T. F. et al. IPCC: Summary for policymakers in climate change 2013: the physical science basis, contribution of working group I to the fifth assessment report of the Intergovernmental Panel on Climate Change. 2013. Cambridge University Press. (2013)

8. Telemeco, R. S., Abbott, K. C. \& Janzen, F. J. Modeling the effects of climate change-induced shifts in reproductive phenology on temperature-dependent traits. The American Naturalist 181(5), 637-648, doi:10.1086/670051 (2013).

9. Luzio, A., Santos, D., Fontaínhas-Fernandes, A. A., Monteiro, S. M. \& Coimbra, A. M. Effects of $17 \alpha$-ethinylestradiol at different water temperatures on zebrafish sex differentiation and gonad development. Aquatic Toxicology 174, 22-35, doi:10.1016/j. aquatox.2016.02.003 (2016)

10. Laloë, J. O., Esteban, N., Berkel, J. \& Hays, G. C. Sand temperatures for nesting sea turtles in the Caribbean: Implications for hatchling sex ratios in the face of climate change. Journal of Experimental Marine Biology and Ecology. 474, 92-99, doi:10.1016/j. jembe.2015.09.015 (2016)

11. Brown, A. R. et al. Climate change and pollution speed declines in zebrafish populations. PNAS 112(11), E1237-E1246, doi:10.1073/ pnas1316269112 (2015)

12. White, J. W., Cole, B. J., Cherr, G. N., Connon, R. E. \& Brander, S. M. Scaling up endocrine disruption effects from individuals to populations: outcomes depend on how many males a population needs. Environmental Science \& Technology. (2017)

13. Ospina-Alvarez, N. \& Piferrer, F. Temperature-dependent sex determination in fish revisited: prevalence, a single sex ratio response pattern, and possible effects of climate change. PLoS One. 3(7), e2837, doi:10.1371/journal.pone.002837 (2008).

14. Duffy, T. A., McElroy, A. E. \& Conover, D. O. Variable susceptibility and response to estrogenic chemicals in Menidia menidia. MEPS 380, 245-254, doi:10.3354/meps07928 (2009).

15. Brander, S. M. Thinking outside the box: Assessing endocrine disruption in aquatic life. Monitoring water quality: pollution assessment. analysis, and remediation. 2, 103-47. Elsevier, Waltham, MA, 2013)

16. Jin, M. et al. Developmental toxicity of bifenthrin in embryo-larval stages of zebrafish. Aquatic Toxicology 95(4), 347-354, doi:10.1016/j.aquatox.2009.10.003 (2009).

17. Cloern, J. E. \& Jassby, A. D. Drivers of change in estuarine-coastal ecosystems: Discoveries from four decades of study in San Francisco Bay. Reviews of Geophysics, 50(4), doi:10.1029/2012RG000397 (2012).

18. Brander, S. M. et al. Transcriptomic changes underlie altered egg protein production and reduced fecundity in an estuarine model fish exposed to bifenthrin. Aquatic Toxicology 174, 247-260, doi:10.1016./j.aquatox.2016.01.014 (2013).

19. Pankhurst, N. W. \& Munday, P. L. Effects of climate change on fish reproduction and early life history stages. Marine and Freshwater Research 62(9), 1015-1026, doi:10.1071/MF10269 (2013).

20. Breckels, R. D. \& Neff, B. D. The effects of elevated temperature on the sexual traits, immunology and survivorship of a tropical ectotherm. Journal of Experimental Biology 216, 2658-2664, doi:10.1242/jeb.084962 (2013).

21. Kuivila, K. M. et al. Occurrence and Potential Sources of Pyrethroid Insecticides in Stream Sediments from Seven U.S. Metropolitan Areas. Enviornmental Science and Technology 46(8), 4207-4303, doi:10.1021/es2044882 (2012). 
22. King, O. C., van de Merwe, J. P., McDonald, J. A. \& Leusch, F. D. L. Concentrations of levonorgestrel and ethinylestradiol in wastewater effluents: is the progestin also cause for concern? Environmental Toxicology and Chemistry. 35(6), 1378-1385, doi:10.1002/etc.3304 (2016).

23. Brander, Susanne M., Bryan J. C. \& Gary N. Cherr. An approach to detecting estrogenic endocrine disruption via choriogenin expression in an estuarine model fish species. Ecotoxicology 21(4), 1272-1280 (2012).

24. Forsgren, K. L., Riar, N. \& Schlenk, D. The effects of the pyrethroid insecticide, bifenthrin, on steroid hormone levels and gonadal development of steelhead (Oncorhynchus mykiss) under hypersaline conditions. General and Comparative Endocrinology 186, 101-7, doi:10.1016/j.ygcen.2013.02.047 (2013).

25. DeGroot, B. C. \& Susanne, M. Brander. The role of P450 metabolism in the estrogenic activity of bifenthrin in fish. Aquatic toxicology 156, 17-20 (2014).

26. Clarke, A. \& Fraser, K. P. P. Why does metabolism scale with temperature? Functional Ecology 18(2), 243-251 (2004).

27. Lambert, M. R., Giller, G. S. J., Barber, L. B., Fitzgerald, K. C. \& Skelly, D. K. Suburbanization, estrogen contamination and sex ratio in wild amphibian populations. PNAS, 112(38), doi:10.1073/pnas.1501065112. (2015).

28. Heintz, M. M., Brander, S. M. \& White, J. W. Endocrine Disrupting Compounds Alter Risk-Taking Behavior in Guppies (Poecilia reticulata). Ethology 121, 480-491 (2015).

29. Le Fol, Vincent et al. In vitro and in vivo estrogenic activity of BPA, BPF and BPS in zebrafish-specific assays. Ecotoxicology and Environmental Safety 142, 150-156 (2017).

30. Zerulla, M. et al. Morphological sex reversal upon short-term exposure to endocrine modulators in juvenile fathead minnow (Pimephales promelas). Toxicology letters 131(1), 51-63 (2002).

31. Hubbs, C. Life history dynamics of Menidia beryllina from Lake Texoma. American Midland Naturalist. 1(1-2), doi:10.2307/2425184 (1982).

32. Conover, D. O., Fleisher, M. H. Temperature-sensitive period of sex determination in the Atlantic silverside, Menidia menidia. Canadian journal of fisheries and aquatic sciences. 43(3), 514-20 (1986).

33. Brander, S. M. et al. From 'omics to otoliths: responses of an estuarine fish to endocrine disrupting compounds across biological scales. PloS one. 8(9), e74251 (2013).

34. Xue, J. et al. Development of passive samplers for in situ measurement of pyrethroid insecticides in surface water. Environmental Pollution 224, 516-523 (2017).

35. Burgess, S. C. \& Marshall, D. J. Adaptive parental effects: the importance of estimating environmental predictability and offspring fitness appropriately. Oikos. 123(7), 769-76, doi:10.1111/oik.01235 (2014).

36. Palmquist, Katherine, Johanna Salatas \& Anne Fairbrother. Pyrethroid insecticides: use, environmental fate, and ecotoxicology. Insecticides-Advances in Integrated Pest Management. InTech (2012).

37. Coulter, D. P., Höök, T. O., Mahapatra, C. T., Guffey, S. C. \& Sepúlveda, M. S. Fluctuating water temperatures affect development, physiological responses and cause sex reversal in fathead minnows. Environmental science \& technology. 49(3), 1921-8, doi:10.1021/ es5057159 (2015)

38. Linares-Casenave, J., Werner, I., Eenennaam, J. P. \& Doroshov, S. I. Temperature stress induces notochord abnormalities and heat shock proteins expression in larval green sturgeon (Acipenser medirostris Ayres 1854). Journal of Applied Ichthyology. 29(5), 958-67, doi:10.1111/jai.12220 (2013).

39. Corrales, J., Thornton, C., White, M. \& Willett, K. L. Multigenerational effects of benzo [a] pyrene exposure on survival and developmental deformities in zebrafish larvae. Aquatic Toxicology. 148, 16-26, doi:10.1016/j.aquatox.2013.12.028 (2014).

40. Schwindt, A. R., Winkelman, D. L., Keteles, K., Murphy, M. \& Vajda, A. M. An environmental oestrogen disrupts fish population dynamics through direct and transgenerational effects on survival and fecundity. Journal of Applied Ecology. 51(3), 582-91, doi:10.1111/1365-2664.12237 (2014).

41. Kidd, K. A. et al. Collapse of a fish population after exposure to a synthetic estrogen. Proceedings of the National Academy of Sciences 104(21), 8897-8901 (2007).

42. Vajda, A. M. et al. Reproductive disruption in fish downstream from an estrogenic wastewater effluent. Environmental science \& technology 42(9), 3407-3414 (2008).

43. Bhandari, R. K., Frederick S. V. S. \& Donald, E. Tillitt. Transgenerational effects from early developmental exposures to bisphenol A or $17 \alpha$-ethinylestradiol in medaka, Oryzias latipes. Scientific reports 5 (2015).

44. Maack, G. \& Segner, H. Life-stage-dependent sensitivity of zebrafish (Danio rerio) to estrogen exposure. Comparative Biochemistry and Physiology Part C: Toxicology \& Pharmacology 139.1, 47-55 (2004).

45. Farmer T. M., Marschall E. A., Dabrowski K. \& Ludsin S. A. Short winters threaten temperate fish populations. Nature communications. 15(6), doi:10.1038/ncomms8724 (2015).

46. Santidrián Tomillo, P. et al. Climate change overruns resilience conferred by temperature-dependent sex determination in sea turtles and threatens their survival. Global Change Biology. 21(8), 2980-8, doi:10.1111/gcb.12918 (2015).

47. Consuegra, S. \& Rodríguez López, C. M. Epigenetic-induced alterations in sex-ratios in response to climate change: An epigenetic trap. BioEssays 38.10, 950-958 (2016).

48. Benjamini, Y. \& Hochberg, Y. Controlling the false discovery rate: a practical and powerful approach to multiple testing. Journal of the royal statistical society. Series B (Methodological) 289-300 (1995).

49. Hothorn, T., Bretz, F. \& Westfall, P. Simultaneous Inference in General Parametric Models. Biometrical Journal 50(3), 346-363 (2008).

\section{Acknowledgements}

We would like to thank our collaborators in the Connon lab at the University of California, Davis for performing analytical chemistry on water samples. We would like to acknowledge Nathan Burns, Christian Commander and the many undergraduate assistants at the University of North Carolina, Wilmington for invaluable research assistance, and Dr. J. Wilson White for advice on data analysis. SMB and BMD were supported by the California Department of Fish and Wildlife (contract \#E1183010) and the US Environmental Protection Agency (EPA STAR \#835799). BMD received additional support from the Ahuja Water Quality Fellowship and the Francis Peter Fensel Memorial Fellowship. Additional research funds were acquired from a 2011 UNCW Center for Marine Science pilot grant.

\section{Author Contributions}

B.M.D. and S.M.B. designed the experiment. B.M.D. performed the experiment and statistical analyses. S.M.B. advised B.M.D. and provided lab space and equipment. Both authors contributed to writing the manuscript.

\section{Additional Information}

Supplementary information accompanies this paper at doi:10.1038/s41598-017-09631-1

Competing Interests: The authors declare that they have no competing interests. 
Publisher's note: Springer Nature remains neutral with regard to jurisdictional claims in published maps and institutional affiliations.

(c) (i) Open Access This article is licensed under a Creative Commons Attribution 4.0 International License, which permits use, sharing, adaptation, distribution and reproduction in any medium or format, as long as you give appropriate credit to the original author(s) and the source, provide a link to the Creative Commons license, and indicate if changes were made. The images or other third party material in this article are included in the article's Creative Commons license, unless indicated otherwise in a credit line to the material. If material is not included in the article's Creative Commons license and your intended use is not permitted by statutory regulation or exceeds the permitted use, you will need to obtain permission directly from the copyright holder. To view a copy of this license, visit http://creativecommons.org/licenses/by/4.0/.

(c) The Author(s) 2017 